\title{
WORK STRESS AND SUBJECTIVE/PSYCHOLOGICAL WELL-BEING OF EMPLOYEES OF STATE HOLDING COMPANY IN TIMES OF CHANGE
}

\author{
Solveiga Blumberga ${ }^{1}$, Solvita Voronova ${ }^{2}$
}

\begin{abstract}
State Holding Company makes a number of improvements, followed by a process of changes each year. This study was conducted to understand how the changes in the company affect the employees working in it and how the employees deal with the stress caused by such changes. The purpose of the study was to investigate the links between personnel work stress, subjective and psychological well-being of employees during changes in State Holding Company. The research undertakes issues such as: the levels of employee stress and subjective well-being, the levels of employee psychological well-being, links, if any, between subjective and psychological well-being and work stress, and the methods used in the research study. The survey was created with reference to works of other authors such as "Professional Life Stress Scale", "Life Satisfaction Scale" and "Psychological Well-being Survey". It was concluded that the employees had medium levels of stress, medium levels of life satisfaction, and medium levels of overall psychological well-being. There are statistically significant links between subjective well-being, psychological well-being and work stress. Recommendations were prepared for the Human Resources Department to reduce stress levels of personnel working and successful management of changes.
\end{abstract}

UDC Classification: 159.9, DOI: http://dx.doi.org/10.12955/cbup.v4.813

Keywords: subjective, psychological well-being, work stress.

\section{Introduction}

In their job, personnel now-adays experience various changes being made in the company because the development of new technologies and the changing economic situation in the country lead to implementation of changes to improve job processes and quality, and carry out evaluations for efficient use of the resources. State Holding Company makes a number of improvements and introduce new services each year. Organisational and structural changes were initiated in the company to pursue this new development strategy. This study aims at understanding how these changes made in State Holding Company affect the employees working in the company and how the employees deal with the stress caused by these changes.

Stress affects every individual, and it is a major problem these days. Stress is interaction between some force and any encountered resistance, and it remains with people as long as they are exposed to any non-specific requirement, regardless of whether it is short-term or long-term (Selje, 2012). Work stress may be caused by changed processes, style of management, communication with the employees and company culture (Stranks, 2005). Workplace stress is caused by communication, mutual relationship between the colleagues, whether the individual feels understood, appreciated and accepted as a personality and as a professional, and also by the physical factors associated with the well-being of the body (Coja, 2008).

Subjective well-being may be defined as cognitive assessment of emotions in the life of a person. It implies joyful moments, without excluding negative emotions, but marks out high levels of life satisfaction. Positive experience implies high levels of subjective well-being, which is the nucleus of enabling the psychology (Snyder \& Lopez, 2002). Subjective well-being is traditionally defined as life satisfaction and happiness in the aggregate. The definition of psychological well-being, includes its role in development of the individual, challenge and existentialism, and how it manifests in life in general (Keyes, Shmotkin \& Ryff, 2002). Subjective well-being is dependent on the quality of life, its resources, and the satisfaction of the necessary and most essential needs. As a result of this approach, quality of life is described using objective quality indicators, which may be expressed by the following resources: education, income, property, skills, health and others. Diener, Oishi, and Lucas (2003) described subjective well-being as a broad categorical phenomenon which implies human emotional

\footnotetext{
${ }^{1}$ Solveiga Blumberga, Riga International School of Economics and Business Administration, Riga, Latvia, solveigablumberga @gmai.com

${ }^{2}$ Solvita Voronova, Riga International School of Economics and Business Administration, Riga, Latvia
} 
responses, special satisfaction, and global decision regarding life satisfaction. Subjective well-being consists of several temporal events which shape life satisfaction of the individual in the long term, whereas happiness is immediate reflection of the positive or negative influences on the individual (Keyes et al., 2002).

Subjective well-being is the assessment of happiness with regards to joy and painful experiences which largely affects the attitude of a person towards the positive and negative elements in life (Fernandes, Vasconcelos-Raposo, \& Teixeira, 2010). It has been discovered in research studies that, as the individual gets older, the level of subjective well-being does not lower, but increases under positive influences, whereas the negative influences remain stable (Keyes et al., 2002).

Psychological well-being is defined as an indicator of personal growth, based on self-acceptance and acceptance in general, positive relationship with others, individual growth, aim in life, skills in satisfying the everyday needs, and autonomy (Ryff, 1989). It is important for an individual to work and find a sense of life in effort and problems, which is called the purpose in life. Consequently, the centre of psychological well-being is formed as the individual discovers most of their talents and abilities, which is referred to as personal growth (Keyes et al., 2002). Targeted purposes in life and quality relationships with peers are the primary items that positively impact human health (Oishi, 2000). Subjective well-being implies not only indicators of emotional happiness (hedonic well-being), but also cognitive assessment of life satisfaction in general (Keyes et al., 2002). The available empirical data suggests that psychological stability is associated with resistance and recovery from a stress situation, and the basis of positive emotions may be a mechanism with high-level flexibility which enables people to adapt in stress situations quickly. Positive everyday emotions facilitate the ability to resist and help recover from stress sooner (Ong \& Bergeman, 2006).

Changes are an aggregate of planned and structured activities, which by involving the respective employees or their groups, is targeted at improvement of the business results of the organisation, facilitation of development, and changing personnel behaviour. The processes of changes within a company may cause stress in the employees and affect their subjective and psychological well-being. The purpose of the Study is to investigate the links between personnel work stress, subjective and psychological well-beings during changes in State Holding Company.

\section{Methods}

A cluster sample was used in the study. The survey involved 268 respondents, of which $95 \%$ were females and 5\% were males, aged between 40 and 59 years, with secondary school, vocational secondary education, job experience of 21 years or more, and employed at State Holding Company. The methods used in the research study: The survey was created by the authors with reference to Professional Life Stress Scale (Fontana, 1989), Life Satisfaction Scale (Diener, Emmons, Larsen, \& Grifin, 1985), and Psychological Well-being Survey (Ryff, 1989). The research questions were the following: What are the levels of employee stress? What are the levels of employee subjective wellbeing? What are the levels of employee psychological well-being? Are there links between subjective and psychological well-being? Are there links between subjective/psychological well-being and work stress?

\section{Results}

The results of the survey revealed that most of the respondents (85\%) experienced work stress. We believe that, to varying extent, employees are exposed to stress daily, and only a small part of the respondents are not exposed to stress, or are exposed rarely, in their everyday life. Work stress is most frequently caused in employees due to: the volumes of work (21\% of the respondents), unclear job assignments or requirements (21\%), work completion deadlines (15\%), innovations in the company (21\%), and change processes in the company (22\%).

The key to the scale was used to calculate the results of the "Professional Life Stress Scale" (Fontana, 1989). Overall, according to the results of the survey, $44 \%$ of the respondents have low levels of stress, $53 \%$ of the respondents have medium levels of stress, and 3\% of the respondents have high levels of stress. The results obtained in the survey suggest overall medium stress levels among the employees of State Holding Company. 
The "Life Satisfaction Scale" developed by Diener et al. (1985) was used to investigate the life satisfaction of the employees of State Holding Company. This scale can be used to measure an individual's overall assessment of their life. $31 \%$ of the respondents are slightly satisfied with life, 24 $\%$ of the respondents are satisfied with life, $18 \%$ are slightly dissatisfied with life, and $15 \%$ of the respondents are dissatisfied with life. The total score obtained on the scale is 21.2 points, and this corresponds to the value of $21-25$ points (i.e. slightly satisfied with life).

The "Psychological Well-being Survey" of K. Ryff (1989), adapted in Latvia by S. Voitkane and S. Miezite (2001), was used to investigate the psychological well-being of the employees of State Holding Company. The survey consists of 54 statements. The "Psychological Well-being Survey" is used to measure the aspects of psychological well-being on six scales: Mutual Relationship, Autonomy, Ability to Satisfy Daily Needs, Personal Growth, Feeling the Aim in Life and Selfacceptance. The results of the survey are summed up using the key offered for the "Psychological Well-being Survey". With the highest value being 6, the highest score of 4.37 is on the Ability to Satisfy Daily Needs Scale, followed by nearly the same score (4.27) on the Mutual Relationship Scale, 4.02 on the Autonomy Scale, 3.96 on the Feeling the Aim in Life Scale, 3.88 on the Personal Growth Scale, and the lowest score of 3.67 on the Self-acceptance Scale. We believe that, in the aggregate, the Psychological Well-being aspects of the employees of State Holding Company can be considered good.

We used the Spearman's Correlation Coefficient to analyse the links between subjective well-being and work stress, psychological well-being and work stress, and also the correlations between the other obtained data. There is a statistically significant negative correlation $(\mathrm{r}=-.355, \mathrm{p}<0.01)$ between the factors influencing job satisfaction (the Job Scale) and the Professional Life Stress Scale by D. Fontana. The higher the satisfaction with various job-influencing factors, the lower the levels of stress. There is also a statistically negative correlation $(\mathrm{r}=-.339, \mathrm{p}<0.01)$ between the aggregate score on the scales of the survey developed by the authors and the Professional Life Stress Scale by D. Fontana. The more satisfied the employees are with the change processes in State Holding Company, the lower the levels of stress. There is a statistically significant positive correlation $(r=.212, p<0.01)$ between the aggregate score in the survey developed by the authors and the score on the Life Satisfaction Scale by E. Diener et al. (1985). The more the employees enjoy working at State Holding Company, the higher the levels of life satisfaction. There is a statistically significant positive correlation $(r=.236, p$ $<0.01$ ) between the factors influencing job satisfaction (the Job Scale) and the Life Satisfaction Scale by E. Diener et al.. The higher the satisfaction with various job-influencing factors, the higher the levels of life satisfaction. There is a statistically significant negative correlation $(r=-.371$, p < 0.01) between the Professional Life Stress Scale and the Life Satisfaction Scale by E. Diener et al. The higher the levels of stress experienced by the employee, the lower the levels of their life satisfaction. There is a statistically significant negative correlation $(r=-.357, p<0.01)$ between the Mutual Relationship Scale and the Professional Life Stress Scale by D. Fontana. The better the mutual relationship, the lower the levels of stress in the employees. There is a statistically significant positive correlation $(\mathrm{r}=.356, \mathrm{p}<0.01)$ between the Mutual Relationship Scale and the Life Satisfaction Scale by E. Diener et al. The better the mutual relationship, the higher the levels of life satisfaction. There is a statistically significant negative correlation $(r=-.300, p<0.01)$ between the Autonomy Scale and the Professional Life Stress Scale by D. Fontana. The more autonomous the individual, the lower the levels of stress. There is a statistically significant positive correlation $(r=.267, p<0.01)$ between the Autonomy Scale and the Life Satisfaction Scale by E. Diener et al. The more autonomous the individual, the higher the levels of life satisfaction. There is a statistically significant positive correlation $(\mathrm{r}=.481, \mathrm{p}<0.01)$ between the Life Satisfaction Scale and the Ability to Satisfy Daily Needs Scale. The higher the levels of life satisfaction, the better the ability to satisfy the daily needs. There is a statistically significant negative correlation $(r=-.468, \mathrm{p}<0.01)$ between the Ability to Satisfy Daily Needs Scale and the Professional Life Stress Scale by D. Fontana. The better the ability to satisfy the daily needs, the lower the levels of stress. There is a statistically significant negative correlation $(r=-.205, p<0.01)$ between the Professional Life Stress Scale by D. Fontana and the Personal Growth Scale. The lower the levels of stress, the better the opportunities for personal growth. There is a statistically significant negative correlation $(r=-.347, p<0.01)$ between the Professional Life Stress Scale by D. Fontana and the Feeling of Aim in Life Scale. The lower the levels of stress, 
the better the feeling of aim in life. There is a statistically significant negative correlation $(r=-.347, p$ $<0.01$ ) between the Professional Life Stress Scale by D. Fontana and the Self-acceptance Scale. The lower the levels of stress, the higher the levels of self-acceptance. There is a statistically significant positive correlation $(r=0.319, \mathrm{p}<0.01)$ between the Feeling of Aim in Life Scale and the Life Satisfaction Scale by E. Diener et al.. The higher the levels of feeling the aim in life, the higher the levels of life satisfaction. There is a statistically significant positive correlation $(r=0.497, p<0.01)$ between the Life Satisfaction Scale by E. Diener et al. and the Self-acceptance Scale. The higher the levels of life satisfaction, the higher the levels of self-acceptance.

\section{Conclusions and Recommendations}

By carrying out data analyses and interpretation, the authors identified that the employees of State Holding Company had medium levels of stress and that stress in the employees was primarily caused by unclear job assignments, work volumes and insufficient appreciation by the management. To minimise the causes of stress, the employees expect the management to provide detailed explanation of the tasks and requirements and to show appreciation. The levels of subjective well-being meant that the employees of State Holding Company were slightly satisfied with life, with relatively high levels of Psychological Well-being. If the employees have higher levels of satisfaction with various jobinfluencing factors and if the human resources management processes are improved, there will be lower levels of stress in the employees. We identified a statistically significant correlation between subjective well-being and work stress, a statistically significant negative correlation between the Professional Life Stress Scale and the Life Satisfaction Scale. The higher the levels of stress experienced by the employee, the lower the levels of their life satisfaction. Elimination of the stressors will result in lower levels of employee stress and, consequently, higher levels of life satisfaction. There are several statistically significant correlations between subjective, psychological well-being and work stress. It was discovered that there is a statistically significant negative correlation between the Autonomy Scale and the Professional Life Stress Scale, i.e., the more autonomous the individual is, the lower the levels of stress; a statistically significant negative correlation between the Feeling Aim in Life Scale and the Professional Life Stress Scale, i.e., the lower the levels of stress, the better the feeling of aim in life; a statistically significant negative correlation between the Self-acceptance Scale and the Professional Life Stress Scale, i.e., the lower the levels of stress, the higher the levels of self-acceptance; a statistically significant negative correlation between the Ability to Satisfy Daily Needs Scale and the Professional Life Stress Scale, i.e., the better the ability to satisfy the daily needs, the lower the levels of stress; a statistically significant negative correlation between the Mutual Relationship Scale and the Professional Life Stress Scale, i.e., the better the relationship with the colleagues, the lower the levels of stress. The main reason why the employees feel bad is lack of appreciation from the management. The authors suggest that the Human Resources Management Department of State Holding Company should have discussions with the first and second level managers to encourage them to demonstrate appreciation of their subordinates on daily basis, say good words for well performed work, hold discussions with the first and second level managers to encourage them to review the job volumes of their subordinates, and to review if necessary. The Administrative Department should prepare and approve an ordinance regarding the job completion deadlines to fix certain processing and review, approval, signing and internal document turnover timelines, so that every employee knows how many days they have for the processing and review, approval and further advancement of the documents, this potentially resulting in better compliance with the deadlines. The internal communication within State Holding Company should be improved for the employees to be aware of the most significant processes in the company and the instructions, and for them to be referred to the relevant experts in case of any unclear issues. In further professional work, we will have opportunities to carry out personnel management process improvements in State Holding Company by informing its management about the factors which cause stress in the employees and about what the employees expect from the company management in order to minimise and eliminate the causes of stress for higher levels of subjective and psychological wellbeing.

\section{References}

Coja, A. (2008). Mazinām spriedzi darbā: par stresu. Veselība 1, 35-36 [We are reducing the tension at work: for stress. Health 1, 35-36]. 
Diener, E., Emmons, R., Larsen, R., \& Grifin, S. (1985). The Satisfaction With Life Scale. Journal of Personal Assesment, 49 (1). $71-75$

Diener, E., Oishi, S., \& Lucas, R. E., (2003). Personality, Culture, and Subjective Well-Being: Emotional and Cognitive, Evaluations of Life. Annual review of psychology, 54, 403-425 DOI: 10.1146/annurev.psych.54.101601.145056

Fernandes, H. M., Vasconcelos-Raposo, J., \& Teixeira, C. M., (2010). Preliminary Analysis of the Psychometric Properties of Ryff's Scales of Psychological Well-Being in Portuguese Adolescents. The Spanish Journal of Psychology, 13(2), 10321043. DOI: http://dx.doi.org/10.1017/S1138741600002675

Fontana, D. (1989). Professional Life Stress Scale. Adapted from Managing Stress. Leicester: The British Psychological Society and Routledge Ltd.

Keyes, C. L. M., Shmotkin, D., \& Ryff, C. D. (2002). Optimizing well-being: The empirical encounter of two traditions. Journal of Personality and Social Psychology, 82(6) 1007-1022. DOI http://dx.doi.org/10.1037/0022-3514.82.6.1007

Oishi, S. (2000). Goals as Cornerstones of Subjective Well - being: Linking Individuals and Cultures. Cambridge: MIT Press.

Ong, A. D., \& Bergeman, C.S. (eds.) (2006). Psychological Resilience, Positive Emotions, and Successful Adaptation to Stress in Later Life. Journal of Personality and Social Psychology, 91(4), 730-749.

Ryff, C. D. (1989). Happiness Is Everything, or Is It? Explorations on the Meaning of Psychological Well-Being. Journal of Personality and Social Psychology, 57(6):1069-81.

Selje, H. (2012). Mana mūža stress: zinātnieka memuāri. Rīga: Jumava [My life stress: Scientist memoir. Riga: Jumava].

Snyder, C.R., \& Lopez, S.J. (2002). Handbook of positive psychology. Oxford: Oxford University Press.

Stranks, J. (2005). Stress at Work. Oxford: Routledge.

Voitkāne, S., \& Miezīte, S. (2001). Pirmā kursa studentu adaptācijas problēmas. Journal of Baltic Psychology, Vol. 2(1). 4353. 